\section{COMMENTS ON THE PAPER "A DEFINITION OF SEPARATION EFFICIENCY"}

\section{Dear Sir:}

In a recent article (J. Chem. Eng. Japan, 11, 44-47, (1978) Ogawa et al. presented a statistically based definition for assessing the efficiency of separators. The calculation of efficiency is important to a wide variety of industrial separators, not least to those used for the classification of solid particles. The Newton efficiency has been recommended for this purpose (C. Orr, "Particulate Technology", Macmillan, (1966)), although other interpretations of efficiency are available (L. Svarovsky, "Solid-Liquid Separation", Butterworths, (1977) D. C. Freshwater, in "The Scientific Basis of Filtration", ed. K. I. Ives, Noordhoff, (1973)).

One of the prime factors to be considered when defining efficiency must be to identify possible areas of application. The potential deficiencies of the Newton efficiency are clearly pointed out in the paper, primarily that for certain conditions it is too sensitive for smaller product mass fractions and has insufficient detection sensitivity at higher values. The former can, in fact, be an advantage when performance figures of an individual separator are being compared.

The detection sensitivity of the statistical efficiency does not always appear to be any better than that of the Newton efficiency. As an example consider the fine product obtained from an air-swept classifier, which may well have a typical size analysis as given below. To avoid complications arising from losses in the machine assume the coarse product is simply the difference between the feed and the fine product.

A change in conditions led to the minor improvement in fines collection as indicated in the final column. The equiprobable size for the separation is $150 \mu \mathrm{m}$. Efficiency equations such as Newton's or

\begin{tabular}{cccc}
\hline $\begin{array}{c}\text { Size range } \\
{[\mu \mathrm{m}]}\end{array}$ & $\begin{array}{c}\text { Wt. of feed in } \\
\text { size range }\end{array}$ & $\begin{array}{c}\text { Wt. of fines in } \\
\text { size range }\end{array}$ & $\begin{array}{c}\text { Wt. of fines in } \\
\text { size range } \\
\text { after change }\end{array}$ \\
\hline+850 & 3.75 & 0 & 0 \\
$-850+600$ & 29.25 & 0 & 0 \\
$-600+350$ & 114.0 & 6.75 & 4.8 \\
$-350+200$ & 171.0 & 30.15 & 29.7 \\
$-200+150$ & 81.75 & 35.55 & 35.0 \\
$-150+100$ & 88.5 & 52.95 & 53.4 \\
$-100+75$ & 48.75 & 39.0 & 39.4 \\
$-75+5$ & 48.0 & 43.95 & 44.4 \\
-53 & 165.0 & 163.35 & 165.0 \\
\hline & $750.00 \mathrm{~kg}$ & $371.70 \mathrm{~kg}$ & $\frac{371.70 \mathrm{~kg}}{3}$ \\
\hline
\end{tabular}

Ogawa's might well be used here (although neither should be considered as good as a grade efficiency or partition probability determination) in an attempt to quantify the improvement in the separation. Newton's equation gives efficiencies of $67.3 \%$ and $68.9 \%$ before and after the change, whilst Ogawa's gives $35.8 \%$ and $37.7 \%$. Further improvements in the fines separation do not lead to a preference for either equation, in which case Newton's is likely to be chosen on the basis that its concept is more readily understood and less calculation time is required.

The fundamental concept behind Ogawa's definition is a good one, but the result does not always appear to offer advantages over existing methods.

R. J. WAKEMAN

Dept. of Chem. Eng., Univ. of Exeter, Exeter EX4 4QF United Kingdom

Received June 19, 1978.

\section{Dear Sir:}

We express our thanks to Dr. Wakeman for his comments on our paper. We would like to present the following for his consideration.

From the standpoint of practical application of the separation efficiency, the efficiency is expected to satisfy the following requisite in addition to the factors which were included in our paper:

The efficiency changes linearly with the change in various separation parameters. In particular, for higher product mass fractions the efficiency changes relatively rapidly as the separation parameters change.

Let us compare our efficiency with the Newton efficiency on the basis of the example to which Dr. Wakeman referred.

The characteristic efficiency curves under the conditions $x_{F}=0.467, x_{R}=0.135$ and $x_{F}=0.467, x_{P}=0.805$ are shown in Figs. 1 (a) and (b), respectively. As is obvious from these figures, our efficiency shows more of a linear relationship over the entire range of separation parameters than does the Newton efficiency.

For higher product mass fractions, in contrast to the case of the Newton efficiency, the rate of change of our efficiency becomes as large as $x_{P} \rightarrow 1$ or $x_{R} \rightarrow 0$. As Dr. Wakeman calculated, the change of our efficiency for the change of separation conditions to which he referred takes only slightly larger values $(1.9 \%)$ than the Newton efficiency $(1.6 \%)$; however, 

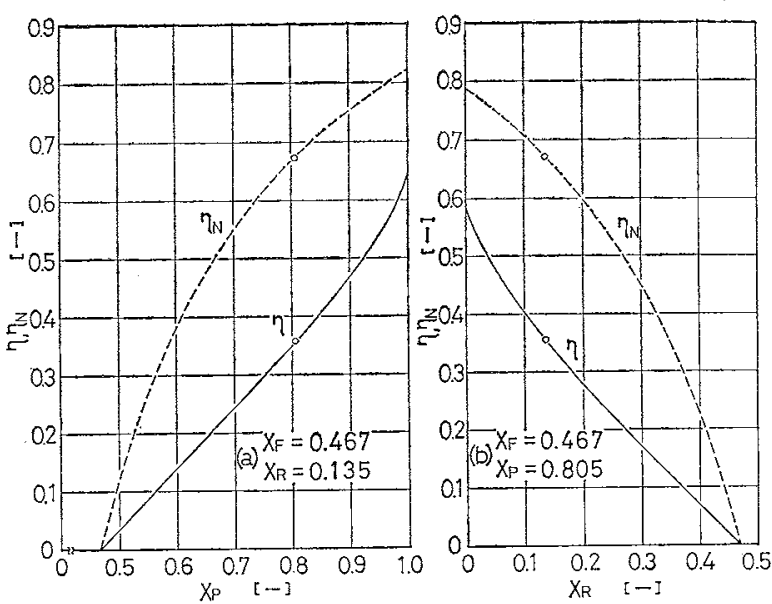

Fig. 1 Comparison of characteristic curves of our efficiency with that of the Newton efficiency under condition of (a) $x_{F}=0.467, x_{R}=0.135$ (b) $x_{F}=$ $0.467, x_{P}=0.805$

if more improvement of separation conditions is made the difference of the change of efficiency between our efficiency and the Newton efficiency will become large and the degree of improvement of separation conditions can be shown more clearly with our efficiency than with the Newton efficiency. Nor can one say that there is no large difference between our efficiency and the Newton efficiency on the basis of almost equal change of efficiency at only one separation condition. Rather, we consider that the
Newton efficiency takes exceedingly large values under the separation condition to which Dr. Wakeman referred.

For lower product mass fractions, the rate of change of our efficiency is smaller than the Newton efficiency; but considering our efficiency changes linearly with the change in separation parameters, one cannot say that our efficiency has a disadvantage when performance figures of an individual separator are being compared.

Our efficiency takes a somewhat larger time to calculate than does the Newton efficiency, as Dr. Wakeman pointed out; however, considering the present state of computer technology, the computation time may be fairly negligible.

Nomenclature

$x_{F} \quad=$ mass fraction of valuable component in feed

$x_{P} \quad=$ mass fraction of valuable component in product

$x_{R} \quad=$ mass fraction of valuable component in residuum

KOHEI OGAWA, SHIRo ITO aNd HideHARU KISHINO Department of Chemical Engineering, Tokyo Institute of Technology, Tokyo 152

Received September 14, 1978. Correspondence concerning this article should be addressed to $\mathrm{K}$. Ogawa.

ERRATA TO VOL. 11 NOS. 4-6 (1978)

\begin{tabular}{|c|c|c|c|c|c|}
\hline No. & Page & Column & Line (b: bottom, $t:$ top) & erroneous & should be $\mathrm{r}$ \\
\hline \multirow[t]{6}{*}{5} & 375 & 1 & $27 \mathrm{t}$ & $8 \times 10^{-3}$ & $8 \times 10^{-7}$ \\
\hline & 392 & Table 3 & & \multicolumn{2}{|c|}{ Change all the values of 0 in the column of $\mathrm{M}$} \\
\hline & 392 & Table 3 & & \multicolumn{2}{|c|}{ Delete 23rd and 24th lines } \\
\hline & 393 & Table 4 & $9 t$ & $\mathrm{BR}$ & $\mathrm{BL}$ \\
\hline & & Table 5 & $7 \mathrm{t}$ & $\mathrm{Fe}(\mathrm{e})$ & $\mathrm{F}(\mathrm{e})$ \\
\hline & 394 & Fig. 4 & $4 \mathrm{t}$ & INVAL $(*)$ & $\operatorname{IVAL}(*)$ \\
\hline
\end{tabular}

Fig. 3

replace the figure by

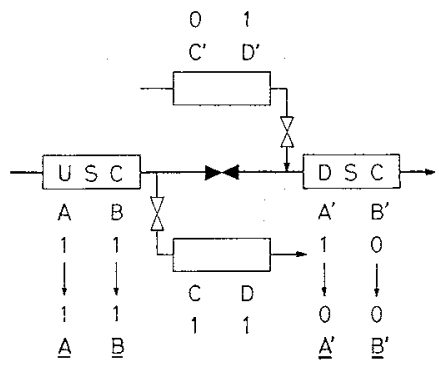

